\title{
ANALISIS TINDAK TUTUR ILOKUSI DI CUITAN AKUN TWITTER @SUDJIWOTEDJO PADA BULAN FEBRUARI 2020
}

\section{ANALYSIS OF THE ILLOCUTIONARY SPEECH ACTS CONTAINED IN THE TWITTERACCOUNT@SUDJIWOTEDJO TWEET IN FEBRUARY 2020}

\author{
Wulan Tri Marwuni, Asep Purwo Yudi Utomo \\ Program Studi Sastra Indonesia, Jurusan Bahasa dan Sastra Indonesia, Fakultas Bahasa dan Seni, \\ Universitas Negeri Semarang, Indonesia \\ Pos-el: wulanmarwuni@students.unnes.ac.id, aseppyu@mail.unnes.ac.id
}

\begin{abstract}
Abstact
Social media is something that cannot be separated from human life today. One of the social media that is loved by the public at this time is Twitter. Its users are not only millennial but also people who are important figures. One of the figures who is still using Twitter is Sudjiwo Tedjo. This study aims to determine the illocutionary speech acts contained in the Twitter account@sudjiwotedjo tweet. In addition, also to find out the characteristics of the account's tweet. The researcher collected the tweets from the@sudjiwotedjo account and then classified the tweets containing illocutionary speech acts in the account. After that, the writer can give the meaning of the tweet which contains illocutionary speech acts. The@sudjiwotedjo account is a positive account even if it's sloppy. It said a positive account because in February 2020, the account several times provided a satire for corruptors and buzzers. His criticism does not only target important people but sometimes also criticizes retaliation from followers. It is said to be a sloppy account because in the tweets the words "asu" and "jancuk" often appear. With this research, it is hoped that Twitter users will be wiser in grasping the meaning in every tweet they encounter.
\end{abstract}

Keywords: twitter, ilocution, tweet, globalization, speech act

\begin{abstract}
Abstrak
Media sosial merupakan sesuatu yang tak dapat terlepas dari kehidupan manusia zaman sekarang. Salah satu media sosial yang digandrungi oleh masyarakat saat ini adalah Twitter. Penggunanya bukan hanya kaum milenial saja, melainkan juga orang-orang yang menjadi tokoh penting. Salah satu tokoh yang aktif menggunakan twitter adalah Sudjiwo Tedjo. Penelitian ini bertujuan mengetahui tindak tutur ilokusi yang terdapat dalam cuitan akun twitter@sudjiwotedjo dan untuk mengetahui karakteristik dari cuitan akun tersebut. Peneliti menggumpulkan cuitan dari akun@sudjiwotedjo kemudian mengklasifikasikan cuitan yang mengandung tindak tutur ilokusi dalam akun tersebut. Setelah itu, penulis memberikan makna dari cuitan yang mengandung tindak tutur ilokusi. Akun@sudjiwotedjo merupakan akun yang positif meskipun urakan. Dikatakan akun positif karena dalam bulan Februari 2020, akun tersebut beberapa kali memberikan sindiran untuk koruptor dan para pendengung. Kritikannya tak hanya menyasar orang-orang penting, tetapi terkadang juga mengritik balasan dari pengikutnya. Dikatakan akun urakan karena dalam cuitannya sering kali muncul kata "asu" dan "jancuk". Dengan adanya penelitian ini diharapkan pengguna Twitter lebih kritis dalam menangkap makna di setiap cuitan yang mereka temukan.
\end{abstract}

Kata Kunci: twitter, ilokusi, cuitan, globalisasi, tindak tutur 


\section{PENDAHULUAN}

Di era globalisasi seperti sekarang ini, penggunaan media sosial tidak dapat terlepas dari kehidupan manusia. Globalisasi berarti meningkatnya pertukaran arus informasi, terbukanya wawasanwawasan baru, dan tersedianya berbagai pilihan dengan skala prioritas untuk menentukan arah tindakan seseorang (Nasution, 2009).

Menurut Andreas Kaplan dan Michael Haenlein dalam Cahyono (2016), media sosial merupakan suatu kelompok aplikasi yang berbasis internet, dibangun di atas dasar ideologi dan teknologi Web 2.0 serta memungkinkan penciptaan dan pertukaran user-generated content. Media sosial merupakan salah satu platform yang muncul di media siber dan digunakan sebagai sarana sosial di dunia virtual (Nindya, 2019). Ningrum, Suryadi, \& Wardhana (2018) memiliki pendapat bahwa media sosial atau medsos telah menjadi bagian dari kehidupan masyarakat Indonesia yang sangat fenomenal.

Saat ini, media sosial tak hanya digunakan oleh kalangan remaja dan dewasa. Para orang tua dan anak-anak juga turut menggunakan media sosial. Salah satu media sosial yang saat ini tengah digandrungi oleh khalayak ramai adalah Twitter. Menurut Olenti, Charlina, \& Hermandra (2019), twitter adalah media sosial yang berguna untuk mengunggah video dan foto, serta pengguna twitter tersebut juga dapat mengungkapkan kata yang terkadang berisikan tentang kemarahan, rasa sedih, dan bahagia. Penggunannya pun menyeluruh ke semua orang, tak terkecuali figur publik. Salah satu figur publik yang aktif menggunakan twitter adalah Sudjiwo Tedjo dengan akun twitter (a)sudjiwotedjo.

Budayawan adalah seseorang yang bertugas untuk mengarahkan gerak langkah kehidupan (budaya) manusia menuju falah, yaitu kebahagiaan dan keberuntungan yang mesti dicapai oleh setiap manusia (Kholil, 2011). Agus Hadi Sudjiwo merupakan seorang budayawan yang lahir di Jember, Jawa Timur, tanggal 31 Agustus 1962. Dia lebih dikenal dengan nama Sudjiwo Tedjo. Selain sebagai budayawan, dia juga seorang penulis yang aktif menulis buku dan rubrik. Saat ini, Sudjiwo Tedjo masih aktif menggunakan sosial media twitter dengan akun@sudjiwotedjo serta sering membuat cuitan berisi kritik yang disampaikan secara tidak langsung.

Setiap pengguna akun twitter pasti akan aktif membuat cuitan. Cuitan tersebut dimaknai berbagai hal oleh para pembaca. Cuitan tersebut dapat dianalisis menggunakan pragmatik. Indrayanti (2016) mengemukakan, bila tata bahasa menggarap kesatuan-kesatuan statis yang abstrak seperti kalimat-kalimat (dalam sintaksis), maka pragmatik menggarap tindak-tindak verbal atau performansiperformansi yang berlangsung di dalam situasisituasi khusus dalam waktu tertentu. Maksudnya adalah pragmatik menggarap bahasa dalam tingkatan yang lebih konkret daripada tata bahasa. Dalam pragmatik terdapat berbagai hal yang dibahas, salah satunya adalah tindak tutur.

Menurut Apriastuti (2017), tindak tutur merupakan sarana mengekspresikan pikiran dan perasaan. Menurut Chaer dalam Hardiati (2018), tindak tutur adalah gejala individual yang bersifat psikologis dan keberlangsungannya ditentukan oleh kemampuan bahasa si penutur dalam menghadapi situasi tertentu. Dalam tindak tutur yang dilihat adalah makna dari tindakan atas tuturannya. Alviah (2014) memiliki pendapat bahwa tindak tutur memiliki beragam maksud yang dapat diidentifikasi dengan mempertimbangkan konteks pertuturannya.

Menurut Searle dalam Sari (2012), tindak tutur secara pragmatis dapat diklasifikasikan menjadi tiga jenis tindak tutur. Ketiga tindak tutur tersebut terdiri atas tindak tutur lokusi atau locutionary acts, tindak tutur ilokusi atau illocutionary acts, dan tindak tutur perlokusi atau perlocutionary acts. 
Tindak lokusi adalah untuk menyatakan sesuatu dan hanya bersifat informative (Wiranty, 2016). Tindak ilokusi berkaitan dengan siapa bertutur, kepada siapa, kapan, dan di mana tindak tutur dilakukan (Rahma, 2018). Menurut (Riyadi, 2019), ilokusi adalah suatu tuturan yang memiliki daya tertentu. Efek yang ditimbulkan dari tuturan perlokusi mempunyai maksud yaitu antara untuk menyindir, berharap/menginginkan dan mempengaruhi (Aziz, 2012).

Tujuan penelitian ini adalah (1) Mengetahui tindak tutur ilokusi yang terdapat dalam cuitan twitter@sudjiwotedjo pada bulan Februari 2020. (2) Mengetahui karakteristik cuitan twitter @sudjiwotedjo pada bulan Februari 2020.

Banyak pengguna media sosial twitter belum bisa memahami suatu cuitan dengan benar. Hal tersebut sering menimbulkan salah paham. Dengan adanya penelitian ini, diharapkan para pengguna Twitter dapat menangkap makna dari cuitancuitan di platform media sosial tersebut. Selain itu, dengan adanya penelitian ini, diharapkan kesalahpahaman antarpengguna platform media sosial Twitter dapat berkurang.

Dalam dunia Twitter dapat dijumpai berbagai tindak tutur. Salah satu tindak tutur yang dapat ditemukan adalah tindak tutur ilokusi. Cuitan akun (a)sudjiwotedjo dapat berupa tindak tutur ilokusi.

Penelitian ini merujuk pada jurnal berjudul "Analisis Tindak Tutur dalam Akun-Akun Twitter Garis Lucu: Sebuah Tinjauan Pragmatik" karya Winaria Lubis. Persamaan penelitian tersebut dengan penelitian ini adalah sama-sama meneliti tindak tutur di Twitter. Hanya saja dalam jurnal tersebut analisisnya menyeluruh semua tindak tutur, yaitu lokusi, ilokusi, dan perlokusi. Dalam penelitian ini, penulis menganalisis tidak tutur ilokusi di Twitter secara lebih mendalam dan terfokus.

\section{METODE PENELITIAN}

Dalam penelitian ini, penulis menggunakan dua pendekatan, yaitu pendekatan teoretis dan pendekatan metodologis. Pendeketan teoretis yang digunakan dalam penelitian ini adalah pendekatan pragmatik. Data dianalisis dengan menggunakan ilmu kajian pragmatik. Menurut Leech (1993), upaya untuk menguak hakikat bahasa tidak akan membawa hasil yang diharapkan tanpa didasari pemahaman terhadap pragmatik, yakni bagaimana bahasa itu digunakan dalam komunikasi. Leech (1993) juga mengartikan pragmatik sebagai studi tentang makna dalam hubungannya dengan situasi-situasi ujar (speech situasions).

Hal yang penting dalam pragmatik adalah pengguna bahasa, penggunaan bahasa, dan konteks. Menurut Firmansyah (2018) pendekatan pragmatik mengaitkan bahasa dengan penggunaan bahasa senyatanya dan melibatkan tidak saja unsur-unsur kebahasaan, seperti kata-kata, frasa, atau kalimat, tetapi unsur-unsur di luarnya juga, yang selalu terkait dalam setiap bentuk penggunaan bahasa. Tujuannya adalah mendiskripsikan data dengan pandangan pragmatik berdasarkan sudut pandang pembaca.

Pendekatan metodologis digunakan penulis dalam penelitian ini adalah pendekatan deskripsi kualitatif. Menurut Pangaribuan dalam Yuliarti, Rustono, \& Nuryatin (2015), penelitian kualitatif berupaya menemukan hipotesis, yaitu kaidahkaidah yang ada dalam realitas diamati dengan observasi partisipatis. Digunakannya kedua pendekatan tersebut disebabkan karena penelitian ini bentuknya bukanlah angka-angka melainkan penjelasan atau uraian penjelas. Cara menganalisis data adalah data penelitian yang berupa tindak tutur lokusi dalam cuitan akun twitter@sudjïwotedjo secara langsung lalu mengamati dan mememahami objek tersebut berdasarkan kajian pragmatik.

Dalam analisis data, peneliti mengumpulkan data ilokusi dalam cuitan akun twitter 
@sudjiwotedjo. Teknik yang digunakan peneliti adalah mengelompokkan tindak tutur ilokusi yang ada dalam cuitan akun twitter@sudjiwotedjo. Datadata yang diambil hanya cuitan yang berupa tindak tutur ilokusi. Kemudian peneliti menentukan makna dari tindak tutur ilokusi tersebut. Klasifikasi, makna tersebut dilakukan dengan menganalisis makna yang mengandung kritik dan makna yang mengandung promosi.

Data yang diambil dalam penelitian ini berupa cuitan di akun@sudjiwotedjo pada kurun waktu bulan Februari 2020. Sumber data dalam penelitian ini adalah akun twitter@sudjiwotedjo. Sumber data ini menggunakan sumber data tertulis berupa beberapa cuitan yang menarik untuk dianalisis menggunakan kajian pragmatik. Kemudian peneliti mencatat, menerjemahkan, dan memahami tindak tutur ilokusi dalam cuitan akun twitter @sudjiwotedjo sehingga mendapatkan makna atas tindak tutur tersebut.

\section{HASIL DAN PEMBAHASAN}

Dalam dunia Twitter, sering ditemukan cuitan yang memiliki banyak makna. Cuitan-cuitan tersebut dipahami berbeda-beda oleh para pembaca. Hal tersebut disebabkan oleh bahasa yang digunakan dalam Twitter merupakan bahasa tulis. Menurut Fawziyyah \& Santoso (2017), bahasa berdasarkan fungsi komunikasi digunakan oleh suatu masyarakat untuk bekerja sama, berinteraksi, dan mengidentifikasi diri. Dalam dunia Twitter interaksi yang terjadi kadang kala menimbulkan salah tafsir. Banyak di antara pengguna media sosial yang tidak menyaring dan mencermati apa yang mereka baca. Dalam sebuah cuitan bisa jadi memiliki suatu tindak tutur, entah itu lokusi, ilokusi, maupun perlokusi.

Pada penelitian kali ini, peneliti bermaksud menganalisis tindak tutur ilokusi dalam cuitan akun twitter@sudjiwotedjo pada bulan Februari
2020. Selain itu, disajikan juga karakteristik dari cuitan-cuitan akun tersebut.

\section{Analisis Tindak Tutur Ilokusi}

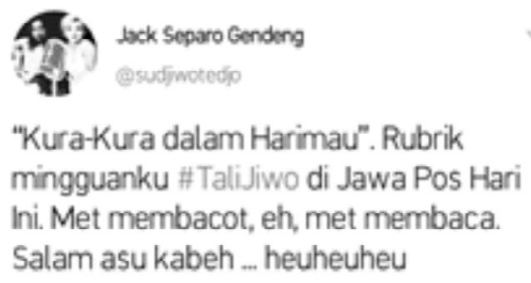

\section{Gambar 1}

Cuitan di atas merupakan salah satu contoh dari tindak tutur ilokusi. Dalam cuitan tersebut, @ sudjiwotedjo bermaksud memberi tahu bahwa rubrik mingguannya telah terbit. Tindak tutur ilokusi dari cuitan tersebut adalah mengajak warganet untuk membaca rubrik mingguannya yang berjudul "Kura-kura dalam Harimau". Hal tersebut dibuktikan dengan adanya frasa "met membaca" yang berarti "selamat membaca".

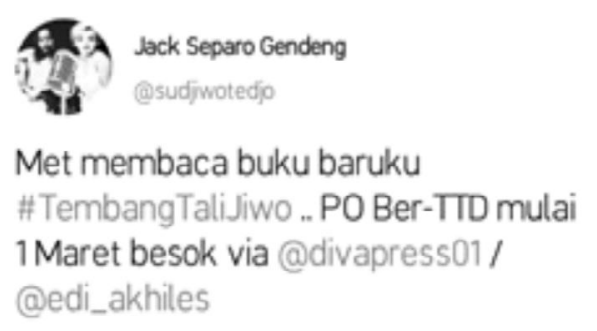

\section{Gambar 2}

Dalam cuitandi atas,@sudjiwotedjo memberi tahu bahwa buku barunya telah terbit. Buku yang berjudul \#TembangTalijiwo dapat di pesan mulai 1 Maret. Secara tidak langsung@sudjiwotedjo sedang melakukan promosi. Promosi tersebut dilakukan agar pembaca cuitannya ikut memesan buku barunya. 


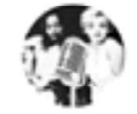

Jack Separo Gendeng

@sudjwotedio

\begin{abstract}
Betul. Penghargaan yg sesungguhnya itu dari alam. Jgn tiru @duniamanji ini. Dia pilih dihargai oleh manusia dgn lagunya yang yaaaaah .. gmn ya. Pdhl laguku \#PadaSebuahRanjang ud 5 tahunan menunggu2 dia nyanyikan sbg single..yg pasti akan menaikkan levelnya di hadapan alam heuheu
\end{abstract}

\section{Gambar 3}

Pada cuitandiatas@sudjowotedjo meminta warganet untuk tidak meniru@duniamanji, @duniamanji memilih dihargai dengan lagunya. Secara ilokusi,@sudjiwotedjo ingin lagunya dinyanyikan oleh@duniamanji. Hal itulah yang menyebabkan@sudjiwotedjo memujinya di bagian akhir cuitan.

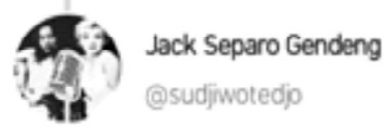

\section{Selama ini tanpa sadar kita melatih diri utk terus2an minder. Lihat Nelson Madela dan Zidane pakai batik, kita bangga. Lihat Richard Gere ngunjungi Borobudur, kita bangga. Mestinya mereka itulah yg harus bangga $\mathrm{krn} \mathrm{dlm}$ hidupnya pernah mengalami Indonesia ... \#NirMinder}

\section{Gambar 4}

Dalam cuitan di atas, @sudjiwotedjo memberi tahu bahwa orang-orang Indonesia itu gumunan. Namun, secara ilokusi, @sudjiwotedjo ingin mengingatkan penduduk Indonesia untuk tidak merasa minder dan jangan gumunan. Para orang asinglah yang seharusnya merasa bangga ketika mengenakan suatu yang khas dari Indonesia. Hal tersebut didukung dengan hashtag di bagian akhir cuitan berupa \#NirMinder yang dapat diartikan tidak minder.

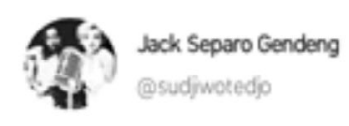

\begin{abstract}
Salam. Kok aku punya feeling bahwa bersabar dan tabah karena batal umroh (krn Arab Saudi menutup sementara), sudah sama dengan umroh itu sendiri. Sori kalau feeling ini keliru.
\end{abstract}

\section{Gambar 5}

Pada cuitan@sudjiwotedjo di atas, dia mengungkapkan feeling-nya. Feeling tersebut dapat mendinginkan suasana. Secara ilokusi, dia meminta orang-orang yang batal umrah untuk bersabar dan tabah, yang terpenting mereka sudah mempunyai niat untuk berangkat umrah meskipun batal karena Arab Saudi ditutup sementara.

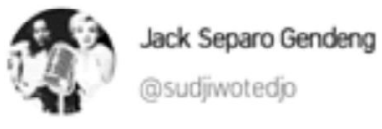

\section{Bagi IQ Berbintang, untuk bisa happy buanyak caranya, tak harus maki2 dan nyerang pribadi orang ... heuheuheu .. sebab \#TuhanMahaAsyik}

\section{Gambar 6}

Cuitan kali ini memberi tahu bahwa happy itu dapat dilakukan dengan banyak cara. Tentu saja cara yang digunakan bukanlah cara-cara yang dianggap buruk. Tindak tutur ilokusinya, yaitu orang-orang pandai tak mungkin, menyerang pribadi orang lain dengan memaki-maki untuk mendapatkan kesenangan. Tak hanya itu, tagar \#TuhanMahaAsyik juga tindak tutur ilokusi sebagai sarana promosi buku karya@sudjinotedjo. 


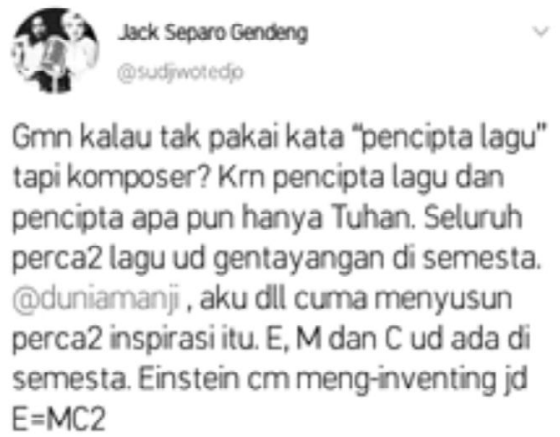

\section{Gambar 7}

Kalimat retorik yang digunakan dalam cuitan di atas menunjukkan ketidaksetujuan. Dalam cuitan tersebut, secara tidak langsung@sudjinvotedjo menyatakan bahwa dia kurang setuju dengan istilah "pencipta lagu". Hal tersebut dikarenakan takut menyaingi Tuhan sang pencipta segalanya. Istilah tersebut mungkin dapat diganti dengan komposer.

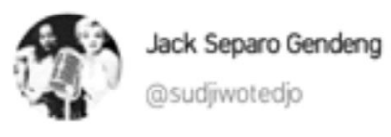

Tidak setuju pemidanaan tokoh yang berpendapat bahwa perempuan bisa hamil di kolam renang, dgn tuduhan membuat berita bohong. Karena, pertama, blm tentu dia punya niat berbohong. Jika punya niat, emang dia satu2 pejabat yang berniat membuat berita bohong? Bisa penuh penjara nanti

\section{Gambar 8}

Dalam cuitan tersebut,@sudjiwotedjo tidak setuju atas pemidanaan tokoh dengan tuduhan berita bohong. Cuitannya kali ini menyasar seorang pejabat. Tindak tutur ilokusinya menunjukkan bahwa banyak pejabat punya niat untuk melakukan kebohongan. Jadi, penjara bisa penuh jika semua pejabat mengaku berniat membuat berita bohong.

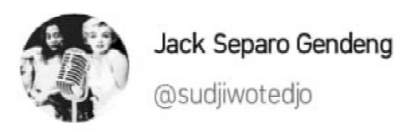

\section{Gmn kalau janjian "Habis Maghrib" dinyatakan ilegal \& dimasukkan pasal baru Omnibus Law? Ini aku di Jkt mau ada tamu janjinya "Habis Maghrib", skrng sudah Isa blm datang juga. Bisa jadi nanti dia nongol pk 22an, tp kan itu "Habis Isa".. rata2 janji "Habis Maghrib" jd "Habis Isa"}

\section{Gambar 9}

Tindak tutur ilokusi dalam cuitan tersebut menunjukkan bahwa adanya kebiasaan orangorang yang ngaret. Jam ngaret sudah seperti tradisi, apalagi dengan waktu janjian yang tidak objektif seperti waktu ibadah. Waktu ibadah dari tempat ke tempat pasti berbeda. Mungkin di satu tempat ujaran "Habis Magrib" adalah pukul 18.15, tetapi di tempat yang lain bisa jadi pukul 18.30 karena waktu magribnya terpaut 15 menit.

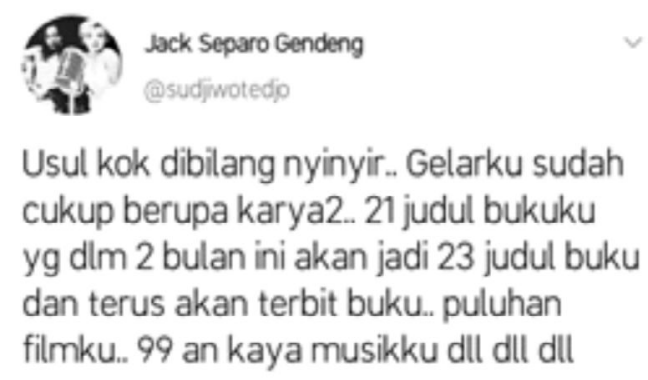

\section{Gambar 10}

Cuitan tersebut menyatakan sanggahan mengenai sebuah balasan yang mengatakan bahwa usulan merupakan nyinyiran. Padahal, nyinyiran dan usulan merupakan dua hal yang berbeda. Ilokusi yang ditunjukkan dalam cuitan@sudjïwotedjo kali ini bermaksud untuk memamerkan karyakarya yang telah dibuatnya. Hal tersebut digunakan untuk membuktikan bahwa usulannya berbobot karena disampaikan oleh orang yang memiliki banyak karya dan bukan sebuah nyinyiran. 


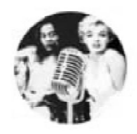

Jack Separo Gendeng

@sudjiwotedjo

Tidak setuju Jok. Kita bukan pensiunan. Yg kita cari bukan kedamaian. Kreativitas kita tak berpijak dari kedamaian, tapi dari kecamuk/gebalau tumpang tindih cover bothside di dalamnya..

\section{Gambar 11}

Cuitan di atas menyatakan suatu ketidaksetujuan, dibuktikan dengan adanya kalimat “Tidak setuju, Jok". Tindak tutur ilokusi yang terdapat di dalamnya adalah bahwa kreativitas dapat muncul dari kecamuk atau suatu kegaduhan bukan dari kedamaian. Selain itu, cuitan tersebut juga menyenggol pensiunan yang biasanya hanya santai-santai dalam kedamaian ketika menikmati masa pensiun.

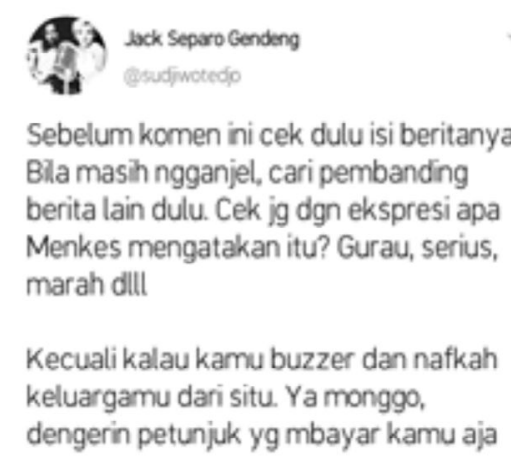

\section{Gambar 12}

Cuitan di atas meminta para pembaca cuitannya untuk mengecek terlebih dahulu isi berita sebelum mengomentarinya. Hal tersebut agar tidak salah paham. Tindak tutur ilokusi yang terdapat dalam cuitan akun@sudjiwotedjo kali ini adalah menyindir para buzzer yang memperkeruh suasana berkaitan dengan ujaran Menkes. Para buzzer tersebut kadang kala menggiring opini sehingga menyebabkan masyarakat bingung mana yang harus dipercaya.

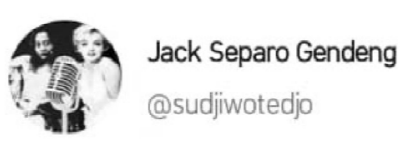

Setuju. Itu kenapa sering kubilang bahwa dosa terbesar koruptor adalah membuat saya merasa suci.

Translate Tweet

IG : kangmaman1965 @maman1965 · 05 Feb

Kita selalu merasa diri sudah PALING SUCI, lalu mudah sekali mengadili moral orang lain.

\section{Gambar 13}

Cuitan tersebut jika diartikan secara lugu memiliki makna bahwa Sudjiwo Tedjo merupakan sosok yang baik. Secara ilokusi, Sudjiwo Tedjo merupakan orang yang lebih baik dibandingkan dengan koruptor. Maksudnya, Sudjiwo Tedjo menyampaikan sindiran bahwa para koruptor merupakan orang yang berdosa. Bahkan, mungkin saja melebihi dirinya.
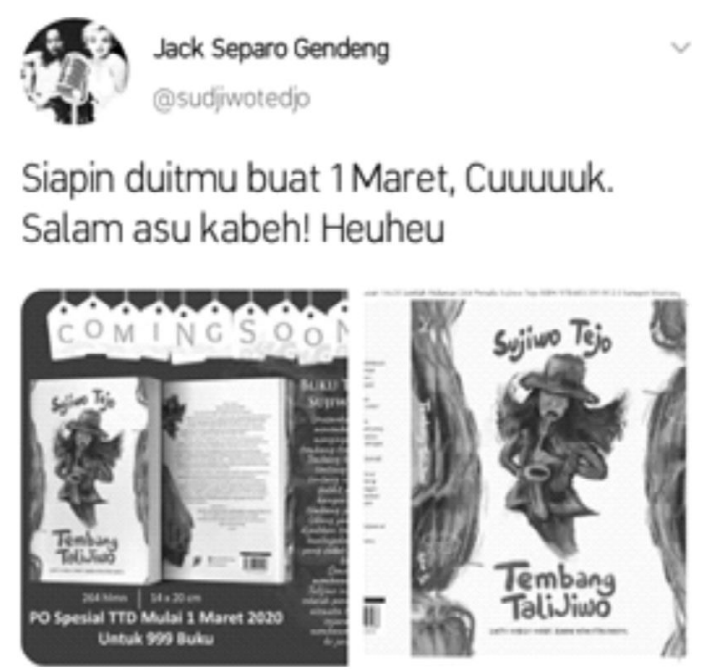

\section{Gambar 14}

Cuitan tersebut jika dipahami secara biasa saja hanya mengandung makna bahwa pembaca cuitannya diminta untuk menyiapkan uang. Namun, cuitan tersebut dapat dipahami dengan 
makna lain setelah ada konteks berupa pengalaman@sudjiwotedjo dalam menerbitkan buku. Ilokusidari cuitan@sudjiwotedjo di atas adalah pada tanggal 1 Maret buku terbarunya akan membuka prapemesanan. Secara tidak langsung, dia meminta warganet untuk turut serta memesannya.

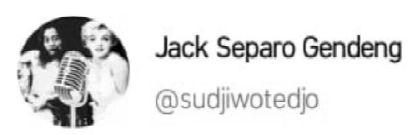

Yg masih mau nonton \#Mangku Jiwo baiknya bawa kantung, jaga2 kalau muntah.. jangan bikin ketar-ketir petugas kebersihan spt di XXI Atrium Jkt ini .. heuheu

Translate Tweet

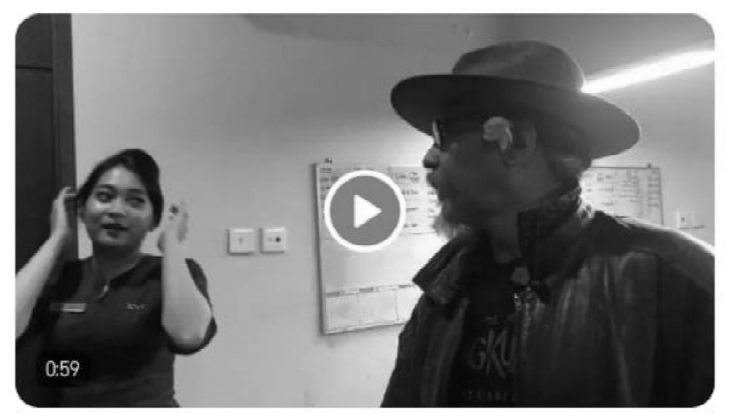

Gambar 15

Jika dipahami secara lugu,@sudjiwotedjo meminta penggemarnya yang akan menonton film terbarunya untuk membawa kantung plastik. Cuitan tersebut mengandung ilokusi. Ilokusi dalam cuitan tersebut bahwa film \#Mangkujiwo merupakan film yang sangat horror sehingga menyebabkan penontonnya muntah. Selain itu, Sudjiwo Tedjo juga bermaksud mempromosikan film terbarunya, dibuktikan dengan adanya tagar \#Mangkujiwo.

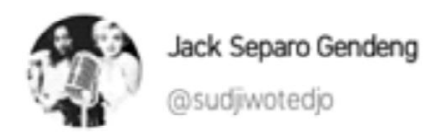

Yg masih gagal paham bahwa koruptor sama bahkan lebih sadis drpd teroris, sila baca rubrik mingguanku \#Tali Jiwo di Jawa Pos hari ini $\boldsymbol{\uparrow}$. Aku bukan cuma bisa nulis twit ttg itu, tp jg bisa nulis artikel di koran bhkn kalau perlu nulis bukunya. Atau sekalian bikin musik dan filmnya

\section{Gambar 16}

Pada cuitan@sudjiwotedjo di atas memiliki ilokusi untuk membaca rubriknya yang telah terbit di Jawa Pos hari itu. Selain itu, cuitan tersebut juga menyenggol para koruptor. Koruptor merupakan sesuatu yang sulit untuk dibasmi sehingga mungkin dapat ditulis menjadi sebuah buku bahkan menjadi lagu dan film. Korupsi adalah suatu hal yang akan terus berlanjut.

\footnotetext{
97 lack Separo Gendeng (1) sudjwotedjo

Yup „, aku jualan sarung jg.. desainku sendiri... selain jualan buku, musik, lukisan, akting dll dll .. Peminat sila hubungi Paspampres \# Jancukers @purpalart .. Ini rahasianya knp aku gak usah nyari nafkah dgn jd buzzer politik. Shg twit2ku suka2 aku bukan krn pesanan heuheu
}

\section{Gambar 17}

Cuitan tersebut memberi tahu bahwa @sudjinsotedjo menjual sarung dan dapat dipesan melalui narahubung yang tersedia. Namun, cuitan tersebut memiliki ilokusi. Ilokusi dalam cuitan tersebut lagi-lagi menyindir para buzzer yang selalu 
mengirim cuitan berdasarkan pesanan dari pemberi nafkah (atasan). Buzzer selalu berhasil mengecoh warganet.

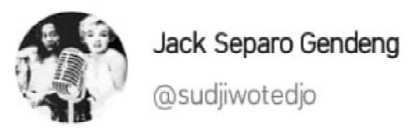

Betul. Robot2 dari Tiongkok kita datangkan. Kita semua berubah jadi pemilik pabrik saja .. jd \#kaumRebahan ..krn menurut bbrp media Omnibus Law lbh ramah ke pemilik pabrik drpd ke tenaga kerja. Nanti kalau Omnibus Law ud tidak ada, nah pabrik kita jual, kita jadi buruh lagi

\section{Gambar 18}

Pada cuitan tersebut, secara lugu Sudjiwo Tedjo mendukung adanya Omnibus Law. Tentu saja dengan kalimat-kalimat yang sangat meyakinkan dan memacu keoptimisan. Namun, jika dianalisis secara ilokusi, cuitan tersebut menyindir pihak yang mengeluarkan Omnibus Law. Omnibus Law dianggap lebih berpihak kepada pemilik pabrik atau pengusaha daripada karyawan atau buruh.

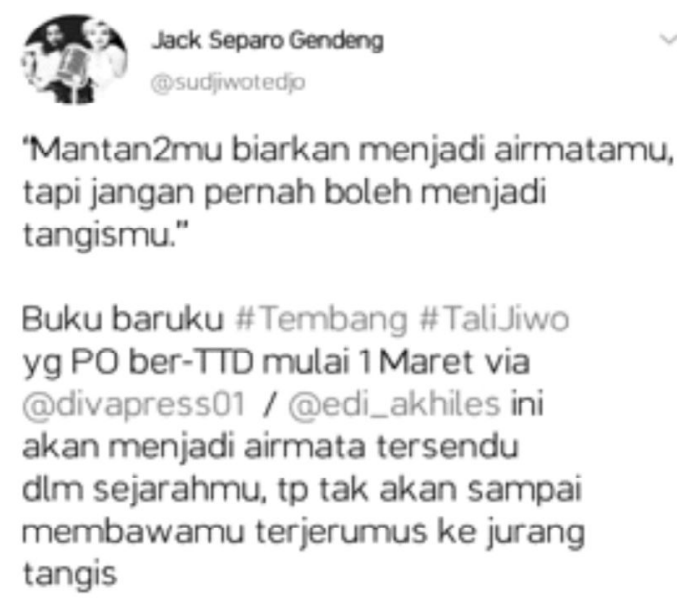

\section{Gambar 19}

Pada cuitan di atas, Sudjiwo Tedjo menuliskan sebuah kutipan. Kutipan tersebut mengenai mantan. Namun, jika dianalisis secara ilokusi bukan itu fokusnya. Sambil memberikan sebuah kutipan, dia juga mempromosikan buku barunya. Hal tersebut juga didukung dengan kalimat meyakinkan pada bagian akhir cuitan.

\section{Karakteristik}

Setiap cuitan pasti mempunyai karakteristik, salah satunya adalah cuitan dalam akun twitter @sudjiwotedjo. Beberapa hal mungkin menonjol dan menjadi ciri khas akun tersebut. Karakterisitik dari cuitan akun twitter@sudjiwotedjo didapat setelah sebelumnya menganalisis tindak tutur ilokusi. Tindak tutur ilokusi yang dianalisis merupakan cuitan dari akun@sudjiwotedjo yang dibuat pada bulan Februari 2020.

Sosok Sudjiwo Tedjo merupakan budayawan yang sering mengkritik apa pun yang dirasa mengganjal. Topik yang sering disinggung adalah koruptor. Cuitan-cuitan yang dibuat sering menyindir mengenai koruptor tetapi disampaikan secara tidak langsung sehingga tidak dapat dipahami dengan membaca sekilas. Tak hanya melalui cuitan, sindiran tentang koruptor juga sering ditemui di rubrik yang ditulisnya.

Akun tersebut merupakan akun yang positif karena banyak memberikan hal-hal baru atau sesuatu yang sebelumnya tidak terpikirkan. Tak dapat dimungkiri bahwa sosok Sudjiwo Tedjo merupakan seseorang yang sering memiliki pikiran lain dari yang lain. Pikiran tersebut terkadang dicuitkan melalui akun twitternya. Hal-hal yang dicuitkan tentu saja merupakan hal yang positif sehingga membuat pembaca cuitannya berfikir logis dan positif.

Akun@sudjiwotedjo merupakan akun yang cukup urakan, pun dengan beberapa pengikutnya. Hal tersebut dibuktikan dengan munculnya kata "asu" pada beberapa cuitan. Tak hanya kata tersebut, istilah \#RebublikJancukers juga tak asing bagi pengikut akun@sudjiwotedjo. Baginya urakan bukan merupakan suatu hal yang tabu. 
Sudjiwo Tedjo merupakan sosok yang kritis. Dalam cuitan di akunnya, dia sering mengkritisi apa pun yang dirasa tidak tepat baginya. Kritiknya tak hanya ditujukan kepada tokoh besar, tetapi juga kadang menyenggol warganet biasa hingga akun berita. Biasanya kritiknya disertai dengan solusi.

Setelah menganalisis cuitan dari akun twitter @)sudjinvotedjo di atas, diharapkan para pengguna twitter dapat memahami suatu cuitan. Hal tersebut harus dilakukan agar tidak terjadi salah paham. Di dunia twitter, salah paham sedikit dapat menimbulkan pertengkaran yang pada akhirnya merugikan banyak pihak. Maka dari itu, sebelum mengirim balasan atas suatu cuitan hendaknya dipahami dulu cuitan yang akan dibalas.

Berdasarkan analisis yang telah dilakukan penulis, hasil yang didapatkan dapat melengkapi analisis dari Winaria Lubis dengan judul "Analisis Tindak Tutur dalam Akun-Akun Twitter Garis Lucu: Sebuah Tinjauan Pragmatik". Dalam penelitian tersebut, penulis hanya menganalisis cuitan di akun-akun twitter garis lucu yang memiliki tindak tutur lokusi, ilokusi dan perlokusi. Dalam penelitian ini penulis menganalis cuitan di akun twitter@sudjiwotedjo yang memiliki tindak tutur ilokusi secara mendalam serta menganalisis karakteristiknya.

\section{PENUTUP}

\section{Simpulan}

Setelah menganalisis tindak tutur ilokusi, dapat disimpulkan bahwa dalam bulan Februari 2020, cuitan@sudjiwotedjo banyak mengandung ilokusi. Ilokusi-ilokusi yang terdapat dalam cuitan tersebut dapat memberi efek untuk menonton filmnya atau membeli buku yang baru saja ia terbitkan. Tak hanya itu, cuitannya sering juga berupa kritik-kritik yang ditujukan kepada orang yang tak adil di negara ini. Terkadang dengan akunnya, sosok Sudjiwo Tedjo juga menyuruh pengikut akun twitternya untuk memahami baca tulis sebelum terjun ke dunia twitter. Hal tersebut agar mereka betul-betul memahami cuitan sebelum menggerakkan jari untuk membalas suatu cuitan. Dari ilokusi-ilokusi yang telah dianalisis tersebut, dapat ditentukan beberapa karakteristik dari cuitan akun@sudjizotedjo tersebut merupakan akun positif yang di dalamnya, sering mengkritik mengenai apa pun yang dirasa tidak tepat baginya. Tak jarang, dia menyenggol akun besar (tokoh) tetapi dia juga sering mengritik balasan dari pengikutnya. Topik yang sering dikritisi adalah korupsi yang telah menjamur di negeri ini. Tak hanya itu, kadang-kadang juga akun@sudjiwotedjo menyindir adanya buzzer-buzzer yang harus menuruti perintah dari sang pemberi uang. Selama bulan Februari 2020, akun tersebut banyak mencuitkan mengenai tindak tutur ilokusi.

\section{Saran}

Membaca sebuah cuitan dalam twitter tidak boleh disepelekan. Pembaca cuitan harus lebih teliti dalam memahami sebuah tweet. Hal tersebut dilakukan agar tidak terjadi salah tafsir yang nantinya akan menyebabkan pertengkaran. Selain itu, kesalahpahaman juga akan merugikan banyak pihak.

\section{DAFTAR PUSTAKA}

Alviah, Iin. 2014. "Kesantunan Berbahasa dalam Tuturan Novel Para Priyayi karya Umar Kayam". Seloka: Jurnal Pendidikan Bahasa dan Sastra Indonesia, Volume 3, pp. 128135.

Apriastuti, Ni Nyoman Ayu Ari. 2017. "Bentuk, Fungsi dan Jenis Tindak Tutur dalam Komunikasi Siswa di Kelas IX Unggulan SMP PGRI 3 Denpasar". Jurnal Ilmiah Pendidikan dan Pembelajaran, Volume 1, pp. 3847.

Aziz, Syaiful Reza. 2012. "Tindak Tutur Lokusi dan Perlokusi dalam Novel Surat Kecil 
Untuk Tuhan Karya Agnes Davonar" (Disertasi, Universitas Muhammadiyah Surakarta).

Cahyono, Anang Sugeng. 2016. "Pengaruh Media

Sosial Terhadap Perubahan Sosial Masyarakat di Indonesia". Jurnal Publiciana, Volume 9, pp. 140-157.

Fawziyyah, Safynatul, and B. Wahyudi Joko Santoso. 2017. "Implikatur Percakapan pada Iklan Kosmetik di Televisi: Kajian Pragmatik". Seloka: Jurnal Pendidikan Bahasa dan Sastra Indonesia. Volume 6, pp. 323330.

Firmansyah, Mochamad Bayu. 2018. "Evaluasi

Pembelajaran Bahasa Berbasis Lingkungan:

Perspektif Pendekatan Pragmatik". STKIP PGRI Pasuruan.

Hardiati, Wiwin. 2018. "Tindak Tutur Sarkastik di Media Sosial (Sarcastic Speech Acts in Social Media)". Jurnal Bahasa, Sastra, dan Pembelajarannya, Volume 8, pp. 123131.

Indrayanti, Novita. 2016. "Tindak Tutur Ilokusi dalam Wacana Naskah Drama 'Deleilah Tak Ingin Pulang dari Pesta' karya Puthut E.A". Universitas Negeri Semarang.

Kholil, M. 2011. "Persoalan Limitasi Budaya dan Sastra Islam". Lingua: Jurnal Ilmu Bahasa dan Sastra, Volume 1, pp. 70-85.

Leech, G. 1993. Prinsip-prinsip Pragmatik. Jakarta: Universitas Indonesia.

Lubis, Winaria. 2019. "Analisis Tindak

Tutur dalam Akun-akun Twitter Garis Lucu Sebuah Tinjauan Pragmatik”. Bahastra: Jurnal Pendidikan Bahasa dan Sastra Indonesia, Volume 4, pp. 100106.

Nasution, Ikhwanuddin. 2009. "Sastra dan Globalisasi: Tantangan bagi Estetika Dalam Dunia Kritik Sastra di Indonesia”.
Nindya, Ayu Pertiwi. 2019. "Implikatur Pada Meme Dakwah Islam di Media Sosial Instagram (Kajian Pragmatik)". (Disertasi, Universitas Diponegoro).

Ningrum, Dian Junita, dkk. 2018. "Kajian Ujaran Kebencian di Media Sosial". Jurnal Ilmiah KORPUS, Volume 2, pp. 241252.

Olenti, Naomy Ayuna, Charlina, \& Hermandra. 2019. "Tindak Tutur Ekspresif dalam Twitter". Jurnal Tuab: Pendidikan dan Pengajaran Bahasa, Volume 1, pp. 148-155.

Rahma, Anis Nurulita. 2018. "AnalisisTindak Tutur Ilokusi dalam Dialog Film Animasi Meraih Mimpi”. Jurnal Skriptorium, Volume 2, pp. 13-24.

Riyadi, Slamet. 2019. "Jenis Tindak Tutur Ilokusi dan Implikaturnya alam Banner Calon Legislatif Pemilu 2019”. Literasi: Jurnal Penelitian, Pendidikan Bahasa, dan Sastra, Volume 2, pp. 29-42.

Sari, Fenda Dina Puspita. 2012. "Tindak Tutur dan Fungsi Tuturan Ekspresif dalam Acara Galau Finite di Metro TV: Suatu Kajian Pragmatik". Jurnal Skriptorium, Volume 1, pp. 1-14.

Wiranty, Wiendi. 2016. "Tindak Tutur dalam Wacana Novel Laskar Pelangi karya Andrea Hirata (Sebuah Tinjauan Pragmatik)". Jurnal Pendidikan Bahasa, Volume 4, pp. 294-304.

Yuliarti, Rustono, \& Nuryatin, Agus. 2015 “Tindak Tutur Direktif dalam Wacana Novel Trilogi karya Agustinus Wibowo". Seloka: Jurnal Pendidikan Bahasa dan Sastra Indonesia, Volume 4, pp. 78-85. 